\title{
Increased frequency of circulating Th22 in addition to Th17 and Th2 lymphocytes in systemic sclerosis: association with interstitial lung disease
}

\author{
Marie-Elise Truchetet ${ }^{1 \dagger}$, Nicolò C Brembilla ${ }^{1 \dagger}$, Elisa Montanari ${ }^{1}$, Yannick Allanore ${ }^{2,3}$ and Carlo Chizzolini ${ }^{1 *}$
}

\begin{abstract}
Introduction: T cell abnormalities have been associated with the pathogenesis of systemic sclerosis (SSc). Recently, besides T helper (Th)17 cells, the Th22 subset has been identified in humans. Our purpose was to investigate the pattern of cytokines produced and chemokine-receptors expressed by peripheral blood (PB) Th cells in SSc and healthy donors (HD) focusing on cells producing interleukin (IL)-17 and IL-22 and to identify specific clinical associations.
\end{abstract}

Methods: Clinical data and peripheral blood were collected in 33 SSC individuals and 29 HD. IL-17A, IL-22, interferon gamma (IFN- $\gamma$ ), IL-4 production, the chemokine receptors CCR4, CCR6, CCR10, CXCR3 expression and the CD161 Th17 cell marker were assessed by multiparametric flow cytometry in PB CD4+ T cells. Intracellular cytokine accumulation was further investigated in CD4+ T cells expanded in vitro for seven days.

Results: The frequency of Th22, Th17, Th2, but not Th1 cells, was significantly increased in SSc individuals compared to HD. The percentage of CD161+CD4+ T cells was increased in SSC and correlated with the percentage of IL-17A producing cells. Moreover, the expression of the skin- and lung-homing chemokine receptor CCR6 correlated with the frequency of IL-22 and IL-17A-producing cells in SSc but not in HD. Finally, SSc interstitial lung disease (ILD) was strongly associated with higher numbers of IL-22 and, to a lesser extent, IL-17A-producing cells.

Conclusions: IL-22 and IL-17A-producing T cells with skin- and lung-homing capabilities are characteristically increased in SSc. These findings support the hypothesis that Th22, in addition to Th17 cells, may be involved in pathological processes leading to SSc. While the association between IL-22 producing cells and ILD needs to be assessed in larger cohorts of patients, the increased frequency of Th22 cells appears to be a useful novel biomarker in SSC.

\section{Introduction}

Systemic sclerosis (SSc), or scleroderma, is a chronic connective tissue disease characterized by autoimmunity, fibrosis of the skin and internal organs, and vascular dysfunction [1]. While the pathogenic mechanisms of the disease are still largely elusive, a number of findings indicate that the immune response may play a key role [2]. First, antinuclear antibodies (ANA) are

\footnotetext{
* Correspondence: carlo.chizzolini@unige.ch

† Contributed equally

${ }^{1}$ Immunology and Allergy, University Hospital and School of Medicine, 4 rue Gabrielle Perret Gentil, Geneva 1211, Switzerland

Full list of author information is available at the end of the article
}

characteristically present and segregate with distinct clinical presentations. Second, genetic studies indicate that most of the gene polymorphisms associated with SSc involve genes coding for molecules controlling the immune response, shared with other auto-immune disorders like systemic lupus erythematosus (SLE) [3]. Third, histological examination of the skin of patients with SSc during the early edematous inflammatory phase of the disease demonstrates the presence of mononuclear cell infiltrates containing $\mathrm{T}$ cells with perivascular distribution preceding the development of fibrosis and overt vasculopathy [4,5]. Of interest,

\section{C) Biomed Central}


fibroblasts with increased expression of type I and III procollagen mRNA are frequently detected in areas adjacent to mononuclear cell infiltrates suggesting that inflammatory cells, and in particular $\mathrm{T}$ cells, are responsible for the altered functional fibroblast phenotype [6].

Chemokine receptors sense the appropriate ligands in the extracellular environment and transduce the signal directing cell movement [7]. Importantly, in conjunction with adhesion molecules, they determine the combinatorial code used by immune cells to transmigrate across the endothelium and reach target tissues, both in homeostatic and inflamed conditions [8]. CCR4, and to a more limited degree CCR10, contribute to homing into the skin [9-11]. CCR6 has been shown to allow homing into the skin and other tissues including the lung, particularly under inflammatory conditions [11-13]. CD4 + T cells differentiate into a variety of effector subsets, which include $\mathrm{T}$ helper (Th)1, Th2, Th17, and the more recently identified Th22 cells $[14,15]$. Of interest, chemokine receptor distribution is characteristically restricted to discrete Th cell subsets [13,16-18]. Th1 cells mainly produce interferon gamma $($ IFN- $\gamma)$ and are thought to preferentially express CXCR3 [16]. Th2 cells produce interleukin (IL)-4 and when activated preferentially express CCR4 [19]. Th17 cells produce IL-17A, IL-17F and IL-22 and mostly express CCR6 [13]. Moreover, Th17 cells have been recently shown to express the lectin receptor CD161, previously known as a natural killer cell marker [20,21]. IL-22 is produced by many cell types, including Th17 cells and Th1, while Th22 cells characteristically produce IL-22 in the absence of IL-17A and IFN- $\gamma$. Of interest, Th22 are enriched in cells expressing CCR4, CCR6, and CCR10 [17,18].

Th2 cells have been shown to be overrepresented in SSc tissues and to be linked to active disease compared to Th1 cells, since IL-4 has direct pro-fibrotic properties [22-25]. While Th17 cells are thought to play an important role in the induction of autoimmune tissue injury [26], little is known about their role in SSc. However, increased levels of IL-17 were detected in the sera and bronchoalveolar lavage fluid of SSc individuals $[27,28]$, and in a recent study Th17 cells were found to be increased, especially in patients with early diffuse SSc [29]. As far as we know, no studies have yet directly assessed the presence and the functional characteristics of Th22 cells in SSc.

The objective of the present study was to revisit the contribution of various CD4+ T cell subsets to the peripheral cell pool characterizing SSc with major focus on cells producing IL-22 and IL-17A. We studied the chemokine receptor usage for assessing their potential to transmigrate into SSc affected tissues, and verified whether Th cell characteristics distinguishing SSc from healthy individuals (HD) could associate with specific SSc clinical features. The results indicate an SSc-specific increase in the number of Th cells producing IL-22 and IL-17A, skewed to preferential homing into the lung and associated with interstitial lung disease (ILD).

\section{Materials and methods}

\section{Study population}

The peripheral blood of 33 consecutive SSc individuals that satisfied the criteria by LeRoy et al. [30] and who were not receiving disease-modifying drugs, cytokine blocking reagents or immunosuppressant agents were prospectively recruited when presenting at the Rheumatology A Unit of the Cochin hospital during a ninemonth period. Their clinical characteristics are detailed in Table 1. ILD was identified by the presence of typical features on high-resolution computerized tomography (HRCT) of the chest and confirmed by total lung capacity (TLC) lower than $80 \%$ of the predicted value. Pulmonary artery hypertension (PAH) was suggested by an echocardiographic systolic pulmonary arterial pressure > $40 \mathrm{mmHg}$, or a DLCO $<50 \%$ predicted in the absence of pulmonary fibrosis or unexplained dyspnea and confirmed by right heart catheterization and was defined as a mean resting pulmonary artery pressure $>25 \mathrm{mmHg}$ in the presence of a pulmonary capillary wedge pressure $£ 15 \mathrm{mmHg}$ at right heart catheterization. Skin scores were not available and cutaneous involvement was

\section{Table 1 Clinical characteristics of the study populations}

\begin{tabular}{lccc}
\hline Clinical and biological features & SSc (n: 33) & HD (n: 29) & $\boldsymbol{P}$ \\
\hline Women, $\mathrm{n}(\%)$ & $29(87.9)$ & $23(79.3)$ & $\mathrm{ns}$ \\
Age, median (range) & $52(30$ to & $50(18$ to & $\mathrm{ns}$ \\
& $80)$ & $68)$ & \\
Ethnicity: Caucasian (\%) & $30(90)$ & $29(100)$ & $\mathrm{ns}$ \\
Diffuse cutaneous SSc, $\mathrm{n}(\%)$ & $20(60.6)$ & $\mathrm{N} / \mathrm{A}$ & \\
Age onset, mean (+/- SD) & $44(14)$ & $\mathrm{N} / \mathrm{A}$ & \\
Disease duration, median (range) & $7(1$ to 32) & $\mathrm{N} / \mathrm{A}$ & \\
ANA positivity (\%) & $29(87.9)$ & $\mathrm{N} / \mathrm{A}$ & \\
ACA positivity (\%) & $4(12.1)$ & $\mathrm{N} / \mathrm{A}$ & \\
Anti-Scl70 positivity (\%) & $11(33.3)$ & $\mathrm{N} / \mathrm{A}$ & \\
Digital ulcers & $19(57.6)$ & $\mathrm{N} / \mathrm{A}$ & \\
Calcinosis & $9(27.3)$ & $\mathrm{N} / \mathrm{A}$ & \\
Arthritis & $7(21.2)$ & $\mathrm{N} / \mathrm{A}$ & \\
PAH, $\mathrm{n}$ (\%) & $4(12.1)$ & $\mathrm{N} / \mathrm{A}$ & \\
ILD, $\mathrm{n}(\%)$ & $14(42.4)$ & $\mathrm{N} / \mathrm{A}$ & \\
Current immunosuppressive therapy & 0 & $\mathrm{~N} / \mathrm{A}$ & \\
(\%) & & & \\
\hline
\end{tabular}

ANA, anti-nuclear antibodies; ACA, anti-centromere antibodies; ILD, interstitial lung disease; $\mathrm{PAH}$, pulmonary artery hypertension; N/A: not applicable. $P$ as determined by the Fisher's exact test. ILD was observed on HRCT and confirmed by a TLC $<80 \%$ of the predicted value. Pre-capillary PAH was defined as a mean resting pulmonary artery pressure $>25 \mathrm{mmHg}$ in presence of a pulmonary capillary wedge pressure $£ 15 \mathrm{mmHg}$ by a right heart catheterization. 
expressed as limited (ISSc) or diffuse (dSSc) [30]. None of the recruited individuals was under treatment with immunosuppressant agents at the time of blood sampling. Peripheral blood from 29 age- and sex-matched HD was provided by the Blood Transfusion Center (Geneva University Hospital, Switzerland) (Table 1). This study was approved by the ethical committees of the institutions involved and was conducted according to the Declaration of Helsinki. Written informed consent was obtained from all individuals.

\section{Reagents}

Anti-CD3 (clone OKT3) monoclonal antibody (mAb) was obtained from American Tissue Culture Collection (Manassas, VA, USA). Anti-CD4-APC-Cy7 (clone IVT114), antiCD45-RA-FITC (clone HI100), anti-CCR6-PerCP-Cy5.5 (clone 11A9), anti-CCR4-PE-Cy7 (clone 1G1), antiCXCR3-APC (clone 1C6/CXCR3), anti-CD161-APC (clone DX12) and anti-CD28 (clone CD28.2) mAbs came from BD Biosciences (San Jose, CA, USA); anti-IL-4-APC (clone 8D4-8 anti-IFN- $\gamma$-PE-Cy7 (clone 4S.B3) and anti-IL-17AFITC (clone BL168) mAbs were from Biolegend (San Diego, CA, USA); anti-IL-22-PE (clone 142928), antiCCR10-PE (clone 314305) came from R\&D Systems (Abingdon, UK). The Cytofix/Cytoperm fixation/permeabilization solution kit was from Becton Dickinson (San Diego, CA, USA), Ficoll-Paque Plus from GE Healthcare (Uppsala, Sweden), RPMI 1640, phosphate buffered saline (PBS), glutamine, penicillin, streptomycin, trypsin, and fetal calf serum (FCS) from Gibco (Paisley, UK), and phorbol myristate acetate (PMA), $\beta$-mercaptoethanol and brefeldin A from Sigma (St. Louis, MO, USA). Human T-activator CD3/CD28 beads were obtained from Invitrogen (Oslo, Norway) and rhIL-2 from Biogen (Cambridge, MA, USA).

\section{Peripheral blood mononuclear cells (PBMC) culture conditions}

PBMC were cryopreserved in liquid nitrogen until use, then thawed and maintained at $37^{\circ} \mathrm{C}$ for $16 \mathrm{~h}$ in RPMI 1640 supplemented with $1 \%$ nonessential amino acids, $1 \%$ L-glutamine, $1 \%$ sodium pyruvate, $50 \mathrm{U} / \mathrm{ml}$ penicillin, 50 $\mu \mathrm{g} / \mathrm{ml}$ streptomycin, $5 \%$ pooled human AB serum, $5 \%$ FCS and $50 \mu \mathrm{M} \beta$-mercaptoethanol (complete medium) before use. For intracellular cytokine determination, PBMC were either cultured for 24 hours or 7 days upon activation by CD3/CD28 cross-linking. In a 24-hour assay, brefeldin A was added for the last 20 hours. In 7-day cultures IL-2 (20 $\mathrm{U} / \mathrm{ml}$ ) was added at 48 hours and the cells were re-stimulated for FACS analysis with PMA/ionomycin for the last 4.5 hours, in the presence of brefeldin A.

\section{Flow cytometry analysis}

Surface staining was performed using fluorochromeconjugated anti-CD4, anti-CD45RA, anti-CD161, anti-
CCR6, anti-CCR4, anti-CXCR3 and anti-CCR10. In intracellular cytokine determination, the cells were stained with anti-CD4 mAb, fixed and incubated with anti-IL-17A, IL-22, IFN $\gamma$ and IL-4 mAbs using a BD Cytofix/Cytoperm kit according to the manufacturer's instruction. FACS analysis was performed on FACSCanto flow cytometer using FACSDiva (Becton Dickinson) and FlowJo softwares (Tree Star Inc. Ashland, OR, USA). Irrelevant isotype-matched control mAb were used to determine specific staining.

\section{Statistical analysis}

All populations satisfied the Kolmogorov-Smirnov normality test according to GraphPad Prism version 4.00 (Graphpad Software, La Jolla, CA, USA). The significant difference between samples was computed using the Student's $t$ test and correlation between variables using the Pearson correlation coefficient. A $P$-value $<0.05$ was considered statistically significant. Box plots were automatically generated using GraphPad. The box represents values between $25^{\text {th }}$ and $75^{\text {th }}$ percentile with a line at the median $\left(50^{\text {th }}\right.$ percentile). The whiskers extend above and below the box to show the values at the $10^{\text {th }}$ and $90^{\text {th }}$ percentiles.

\section{Results}

Increased frequency of CD4+ T cells producing IL-17A and IL-22 in the peripheral blood of SSc individuals

Several observations support the hypothesis that $\mathrm{T}$ cells are responsible for the altered phenotype of fibroblast and endothelial cells, which ultimately leads to fibrosis in SSc individuals $[4,5,31]$. We aimed at assessing whether in the peripheral blood of a cohort of individuals affected by SSc not receiving disease-modifying drugs, cytokine blocking reagents or immunosuppressant agents, we could detect a peculiar Th cell subset profile when compared to age- and sex-matched HD. To assess the functional repertoire of Th cells, PBMC from individuals affected by SSc and from HD were activated by $\mathrm{CD} 3 / \mathrm{CD} 28$ crosslinking overnight. We then detected the intracellular production of IL-17A, IL-22, IFN- $\gamma$ and IL- 4 in the CD $4+\mathrm{T}$ cell fraction by multiparametric flow cytometry. Confirming previous data $[32,33]$, the frequency of CD4+ T cells was higher in SSc than in HD (data not shown). SSc individuals had significantly increased numbers of CD4+ T cells producing IL-4 in their lymphocyte population compared to controls as previously shown [34], while having similar numbers of IFN- $\gamma$ producing cells (Figure 1A, B). In addition, we observed an increased number of IL-17A and, for the first time, of IL-22 producing cells in SSc (Figure 1B). Interestingly, subgroup analysis showed that IL-17A-producing cells were increased in both $1 S S c$ and $\mathrm{dSSc}$, while the increase in IL-22-producing cells was 
A

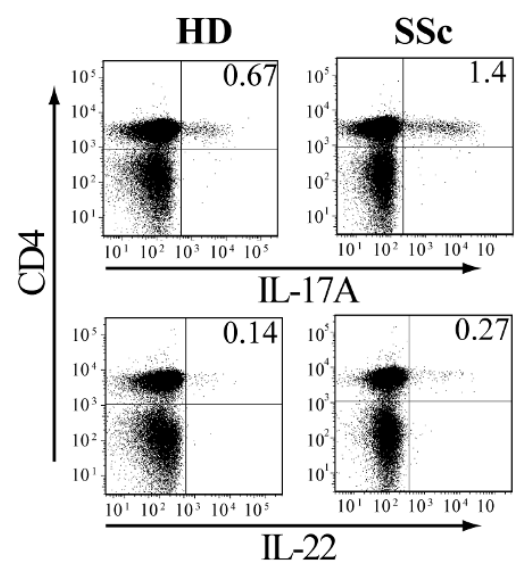

B

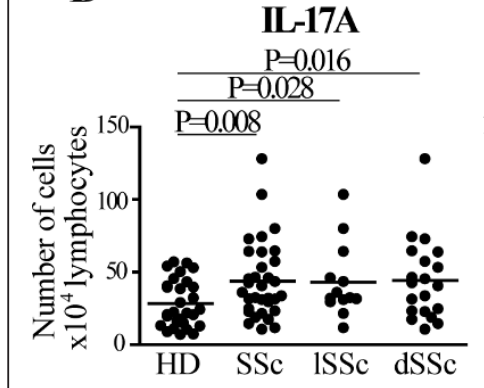

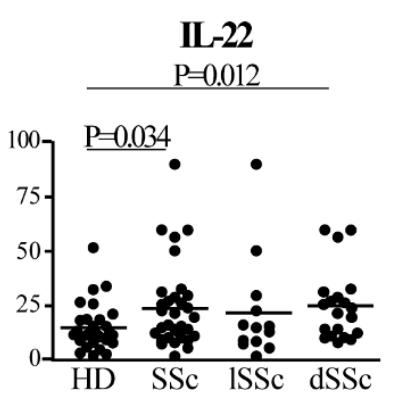

IL-4

Figure 1 The number of IL-17A+ and IL-22+ CD4+ T cells is increased in SSc at Day $\mathbf{0}$. PBMC were activated by CD3/CD28 crosslinking for $24 \mathrm{~h}$ and surface/intracellular stained for FACS analysis. A. FACS plots gated on CD4+ T cells for representative healthy donors (HD) and SSC individuals. Numbers in plots indicate the percentage of IL-17A, IL-22, IFN- $\gamma$ and IL-4 producing CD4+ T cells. B. Numbers of IL-17A, IL-22, IFN- $\gamma$ and IL-4 positive CD4+ T cells for $10^{4}$ living lymphocytes in 29 HD and 33 SSC (IL-17A, IL-22, IFN- $\gamma$ ) or 22 HD and 23 SSC (IL-4) individuals. Shown are significant differences assessed by unpaired t-test. ISSc, limited cutaneous SSC and dSSc, diffuse cutaneous SSc.

observed in dSSc only (Figure 1B). These data indicate that SSc individuals compared to HD have an imbalance in their Th cells populations.

Preferential expansion of single IL-17A+, single IL-22+ and double IL17A+IL-22+ producing CD4+ T cells in SSc Since Th1, Th17 and Th22 cells can all produce IL-22 [35], we investigated whether in SSc individuals IL-22 was produced by the same or by distinct Th subsets. To better discriminate these low frequency subsets, PBMC were expanded in vitro for seven days before intracellular cytokine determination. Consistently with the results obtained with overnight cultures, the frequency of cells producing IL-22 was higher in SSc compared to HD after seven-day culture. This was also true for IL-17A (Figure 2A, B). Among all possible cytokine combinations, SSc individuals had a distinct increased frequency of IL-22 single positive (IL-17A-IL-22+IFN $\gamma$-IL4-cells) which identify the Th22 subset, and of IL-17A+IL-22+ double positive cells characteristic of Th17 cells. In addition, IL-17A single positive cells were also increased in SSc compared to HD (Figure 2A, C). To substantiate such findings, we tested whether the frequency of CD4+ $\mathrm{T}$ cells bearing the CD161 antigen was increased in SSc, since it has been shown that CD161 is preferentially expressed in Th17 cells [21]. This was indeed the case (Figure 3A) and, interestingly, CD161 expression correlated with IL-17A (Pearson $r=0.47, P=0.046$ ) but not IL-22 (Pearson $\mathrm{r}=0.34, P=0.17$ ) production in $\mathrm{SSc}$ (Figure 3Band data not shown). Of note, CD161 was also expressed in non CD4+ cells; however, these cells were not increased in SSc and were not correlated with the production of IL-17A (not shown).

Altogether our data indicate a preferential expansion of IL-22-single, IL-17A-single and IL-17A/IL-22 double producing $\mathrm{CD} 4+\mathrm{T}$ cells in $\mathrm{SSc}$, thus supporting the contention that Th22 cells in addition to Th17 cells are expanded in SSc. 

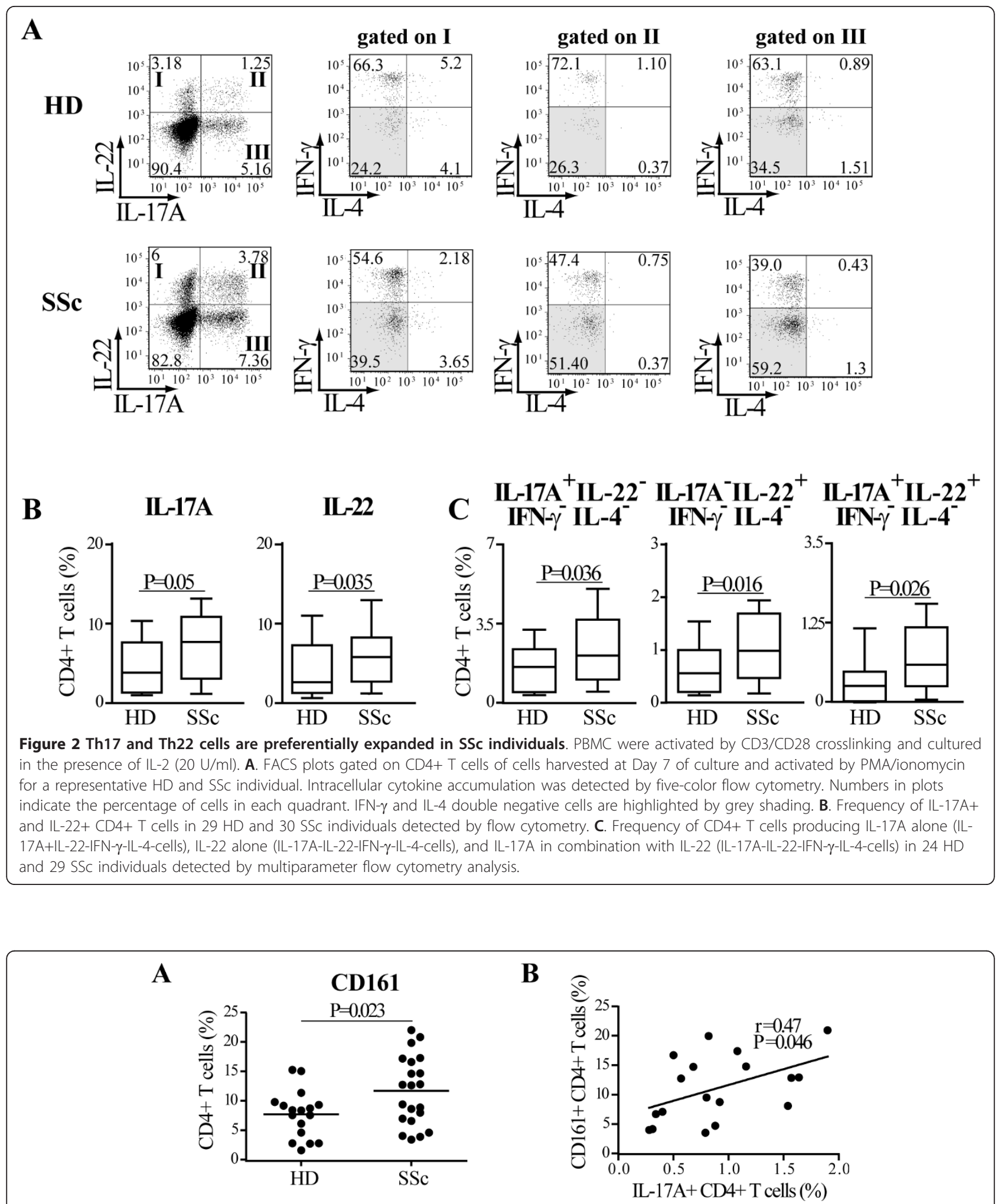

Figure 3 CD161+CD4+ T cells are increased in SSc and correlated with the percentage of IL-17A+CD4+ T cells. A, CD4+CD161+ T cells in the peripheral blood of SSC individuals $(n=21)$ and $\mathrm{HD}(n=17)$ were identified by two-color flow-cytometry analysis. Bars show the means. B, Correlation between the percentage of IL-17A+CD4+ T cells and CD161+CD4+ T cells analyzed ex vivo. For cytokine intracellular localization, the conditions were as described in the legend of Figure 2. A two-tailed unpaired t-test (A) and Pearson correlation (B) were used for statistical analysis. 
CCR6 expression correlates with the frequency of IL-17 and IL-22-producing cells in SSc but not in HD

We then investigated whether SSc individuals had a skewed pattern of lymphocytes expressing chemokinereceptors involved in skin- (CCR6, CCR4 and CCR10) $[10,12]$ and lung-homing (CCR6) $[11,13,36]$. CXCR3, preferentially expressed on Th1 cells, served as control. The expression of CCR6, CCR4, CCR10 as well as CXCR3 on resting peripheral blood memory CD4+ T cells was similar in SSc and HD (Figure 4A). However, CCR6 expression in CD4 $+\mathrm{T}$ cells was positively correlated with the frequency of IL-17A+ and IL-22+ CD4+ $\mathrm{T}$ cells assessed after overnight activation (not shown). Of note, this positive association was observed in SSc but not in HD and was stronger with the CCR6 + CCR10- CD4+ $\mathrm{T}$ cell subset for both IL-17A+ $(\mathrm{r}=$ $0.56, P=0.013)$ and IL-22+ $(r=0.54, P=0.024) \mathrm{CD} 4+$ $\mathrm{T}$ cells (Figure $4 \mathrm{~B}$ ). No significant positive correlations were observed for the other Th subsets with the chemokine receptors studied. Together, these data suggest that IL-17A and IL-22-producing cells in the peripheral blood of SSc but not HD have skin and lung-homing properties.

The frequency of IL-22 producing CD4+ T cells distinguishes SSc individuals according to presence of interstitial lung disease

We finally tested whether the production of specific $\mathrm{T}$ cell cytokines after overnight activation was associated with SSc clinical characteristics. SSc individuals presenting with ILD, as detected by HRCT and decreased TLC, had higher frequencies of IL-22 $(P=0.001)$ and IL-17 producing T-cells $(P=0.05)$ (Figure 5$)$ when compared with those without ILD. Moreover, IL-4 producing Tcells showed a trend to increase in SSc individuals having ILD $(P=0.08)$, while IFN- $\gamma$ producing T-cells did not (Figure 5). Of interest, no differences were observed in the frequencies of cytokine producing cells when considering the gender, $1 S S c$ vs. dSSc, disease duration, presence of digital ulcers or PAH, and ANA positivity thus reinforcing the specificity of our finding.

\section{Discussion}

In the present study, we demonstrate that Th22 and Th17 cells are specifically increased in the peripheral blood of individuals affected by SSc compared to HD. Moreover, the number of IL-17A and IL-22-producing T cells correlated with CCR6 expression in SSc and not in HD, consistent with enhanced skin- and lung-homing properties for these cells under inflammatory conditions. In addition, we identified a strong relationship between high numbers of IL-22 producing T-cells and SSc ILD.

The relatively low number of individuals included limits the power of our study. In addition, we did not have data on disease activity and quantitative evaluation of the skin involvement. However, our cohort was prospectively recruited and the patients included were not receiving disease-modifying drugs, cytokine blocking reagents or immunosuppressant agents at the time of sampling, which strengthen the reliability of our findings.

By applying a multi-parameter cytofluorimetric analysis we found an increased number of CD4+ T cells producing IL-17A and IL-22 in SSc. They were identified as bona fide Th17 and Th22 cells, since single IL-17A+ cells (IL-17A +IL-22-IFN $\gamma$-IL4-), single IL-22+ cells (IL-17A-IL-22 + IFN $\gamma$-IL4-), in addition to double IL-17A+IL-22+ cells (IL-17A+IL-22+IFN $\gamma$-IL4-) were distinctly increased in SSc upon seven days of culture. Although unlikely, we cannot exclude that a small percentage of NKT cells or $\gamma / \delta$

\section{A}

B
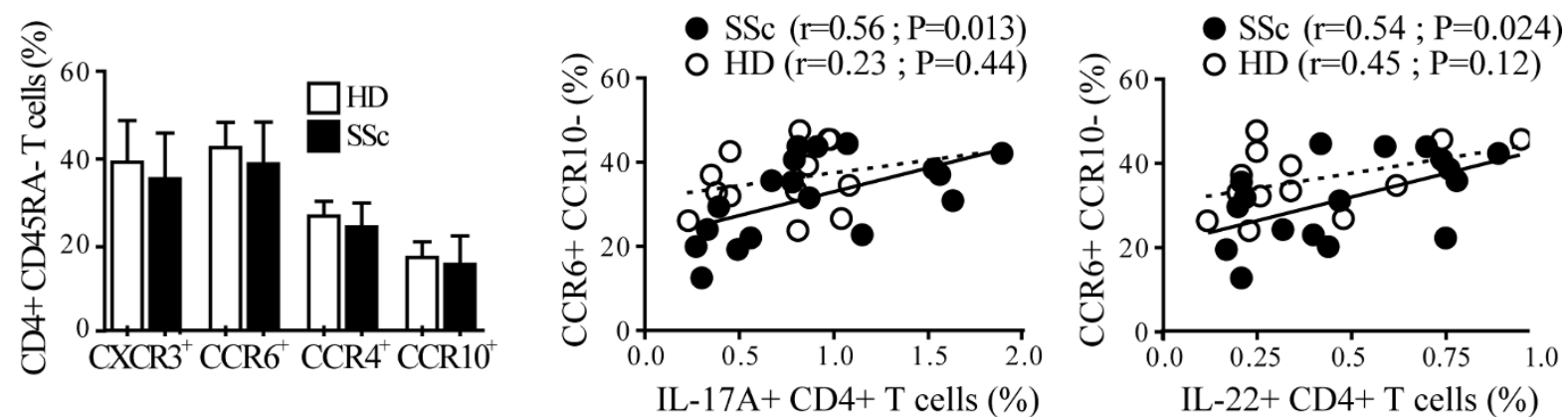

Figure 4 IL-17A and IL-22 production correlates with CCR6+CCR10- expression in SSc CD4+ T cells. A. Frequency of CD4+CD45RA- T cells expressing CXCR3, CCR6, CCR4 or CCR10 in SSC and in HD detected by a six-color flow cytometry. Columns represent mean \pm SD. B. Correlation between the percentages of IL-17+ CD4+ T cells or IL-22+ CD4+ T cells with CCR6+CCR10- in CD4+CD45RA- T cells. Full and empty dots represent SSC and HD, respectively. Continuous and dotted regression lines correspond to SSC and HD, respectively. Pearson correlation was used for statistical analysis. 


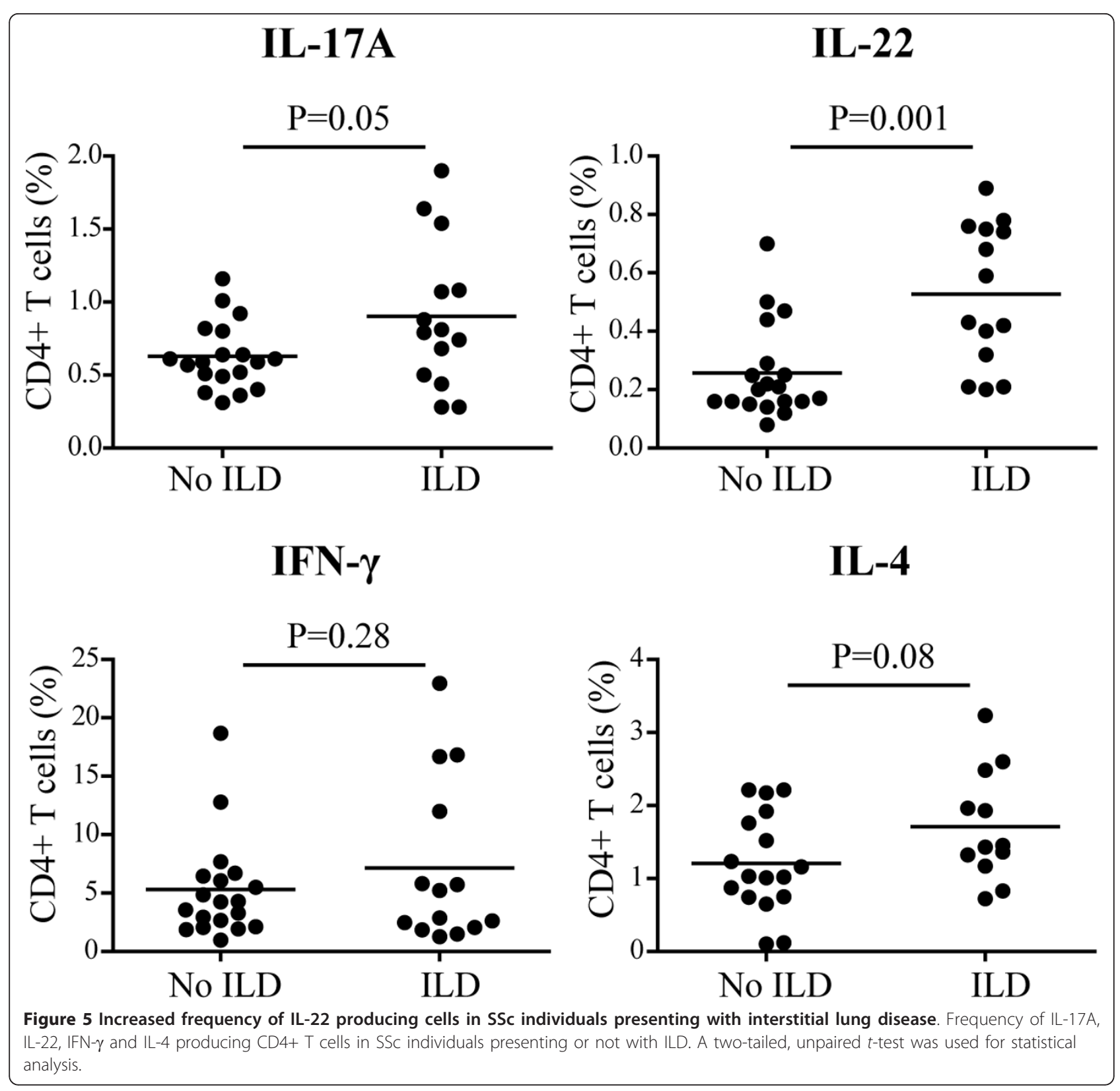

T cells co-expressing CD4 could contribute to IL-17 and IL-22 production in our culture system.

Noteworthy, in SSc, and not in HD, the IL-22 and IL17A $\mathrm{T}$ cell numbers strongly correlated with the expression of CCR6, particularly in the absence of CCR10, which may indicate that these cells are prone to be recruited into inflamed target tissues, specifically in SSc, including the lung. Furthermore, we show for the first time that CD4+ T cells expressing the lectin receptor CD161 are increased in SSc and positively correlate with the number of Th17 cells [20].

Our study is the first to assess the presence and functional characteristics of Th22 cells in SSc. It is interesting to note that Th22 cells appear to play important roles in inflammatory skin disorders. For instance, the frequency of IL-22+ T cells in skin derived T-cell lines from psoriasis, atopic eczema and allergic contact dermatitis was significantly higher than in the peripheral blood [17,37-39]. Furthermore, supernatants of skinderived Th22 clones from psoriatic lesions enhanced wound healing in an in vitro injury model, and transcriptome profiling of epithelial cells submitted to the influence of these clones revealed up-regulation of genes involved in tissue remodeling, angiogenesis and fibrosis [37]. In our cohort of SSc, we found that SSc individuals presenting with ILD had increased numbers of IL-22 
producing cells. The literature is controversial on the possible mechanisms underlying this association. For instance, lung inflammation was ameliorated in IL-22deficient mice receiving high doses of bleomycin compared to IL-22-sufficient mice [40]. On the other hand, protection mediated by IL-22 produced by gamma/delta $\mathrm{T}$ cells has been reported in a mouse model of lung fibrosis induced by hypersensitivity to Bacillus subtilis [41]. While it remains to be established whether the participation of Th22 cells in SSc pathogenic events is harmful rather than protective, their association with ILD suggests an important function of these cells.

Consistent with our findings, IL-17 was previously shown to be increased in the serum and the bronchoalveolar lavage fluid of SSc individuals $[27,28]$. In addition, an increase in Th17 cells in the peripheral blood of SSc was recently reported [29]. What could be the contribution of IL-17 to SSc pathogenesis remains at the moment speculative. IL-17A has been reported to induce IL-6 and IL- 8 production and intercellular adhesion molecule 1 (ICAM-1) expression in human fibroblasts [42]. It should be noticed that IL17A has been shown to participate in an IL-1-dependent manner to the development of bleomycin-induced mouse lung fibrosis [43] and IL-17 may directly stimulate collagen synthesis in rodent fibroblasts $[44,45]$. However, Kurasawa and colleagues could not demonstrate an increased synthesis of type I and III collagen mRNA in human dermal fibroblasts activated by IL-17 [27]. The different responses of mouse and human fibroblasts to IL-17 may be explained by species-specific characteristics. Thus, our data are in line with the hypothesis that Th17 cells in SSc could be more related to inflammation, autoimmunity, and possibly the generation of autoantibodies [46], as it is speculated for several autoimmune disorders non-characterized by fibrosis, including systemic lupus erythematosus and rheumatoid arthritis in which Th17 cells are increased $[26,47,48]$.

\section{Conclusions}

SSc individuals have an increased frequency of circulating IL-22 and IL-17A, producing cells with skin- and lung-homing potential. The association we found between increased numbers of IL-22-producing cells and ILD indicate that Th22 may act as biomarkers to identify individuals at risk and need to be assessed in larger prospective cohorts of patients.

\section{Abbreviations}

ANA: antinuclear antibody; dSSc: diffuse systemic sclerosis; FCS: fetal calf serum; HD: healthy donor; HRCT: high-resolution computerized tomography; IL: interleukin; ILD: interstitial lung disease; IFN-ү: interferon gamma; ISSc: limited systemic sclerosis; mAb: monoclonal antibody; PAH: pulmonary arterial hypertension; PBMC: peripheral blood mononuclear cell; PMA: phorbol myristate acetate; SLE: systemic lupus erythematosus; SSc: systemic sclerosis; Th: T helper; TLC: total lung capacity.

\section{Acknowledgements}

This work was supported in part by grant 31003A_124941/1 from the Swiss National Science Foundation, the Association des Sclérodermiques de France (ASF) and the Groupe français de recherche sur la sclérodermie (GFRS) to CC. MET is supported in part by a grant from the University Hospital of Bordeaux, France and by the Société Française de Rhumatologie (SFR). EM is supported by a grant from the Manodori Foundation, Reggio Emilia, Italy. We thank Mrs Barbara Ruiz (Cochin Hospital, Paris, France) for her skillful technical help and Dr. Camillo Ribi (Geneva University Hospital, Switzerland) for assistance with statistical analysis.

\section{Author details}

${ }^{1}$ Immunology and Allergy, University Hospital and School of Medicine, 4 rue Gabrielle Perret Gentil, Geneva 1211, Switzerland. ${ }^{2}$ Service de Rhumatologie A, Hôpital Cochin, Paris Descartes University, 27 rue du Faubourg SaintJacques, Paris 75679, France. ${ }^{3}$ INSERM U1016, Institut Cochin, Sorbonne Paris Cité, Paris Descartes University, 27 rue du Faubourg Saint-Jacques, Paris 75014, France.

\section{Authors' contributions}

MET and NCB conceived the experiments, performed research, analyzed the data and drafted the manuscript. EM performed research. YA provided samples from SSc individuals and critically revised the manuscript. CC conceived research, analyzed the data and drafted the manuscript. All authors read and approved the final manuscript.

\section{Competing interests}

The authors declare that they have no competing interests.

Received: 9 June 2011 Revised: 19 August 2011

Accepted: 13 October 2011 Published: 13 October 2011

\section{References}

1. Gabrielli A, Avvedimento EV, Krieg T: Scleroderma. N Eng J Med 2009, 360:1989-2003

2. Chizzolini C: Update on pathophysiology of scleroderma with special reference to immunoinflammatory events. Ann Med 2007, 39:42-53.

3. Allanore Y, Dieude P, Boileau C: Genetic background of systemic sclerosis: autoimmune genes take centre stage. Rheumatology (Oxford) 2010, 49:203-210.

4. Prescott RJ, Freemont AJ, Jones CJ, Hoyland J, Fielding P: Sequential dermal microvascular and perivascular changes in the development of scleroderma. J Pathol 1992, 166:255-263.

5. Kalogerou A, Gelou E, Mountantonakis S, Settas L, Zafiriou E, Sakkas L: Early T cell activation in the skin from patients with systemic sclerosis. Ann Rheum Dis 2005, 64:1233-1235.

6. Scharffetter K, Lankat-Buttgereit B, Krieg T: Localization of collagen mRNA in normal and scleroderma skin by in-situ hybridization. Eur J Clin Invest 1988, 18:9-17.

7. Allen SJ, Crown SE, Handel TM: Chemokine: receptor structure, interactions, and antagonism. Annu Rev Immunol 2007, 25:787-820.

8. Bromley SK, Mempel TR, Luster AD: Orchestrating the orchestrators: chemokines in control of T cell traffic. Nat Immunol 2008, 9:970-980.

9. Campbell JJ, O'Connell DJ, Wurbel MA: Cutting edge: Chemokine receptor CCR4 is necessary for antigen-driven cutaneous accumulation of CD4 T cells under physiological conditions. J Immunol 2007, 178:3358-3362.

10. Soler D, Humphreys TL, Spinola SM, Campbell JJ: CCR4 versus CCR10 in human cutaneous TH lymphocyte trafficking. Blood 2003, 101:1677-1682.

11. Reiss Y, Proudfoot AE, Power CA, Campbell JJ, Butcher EC: CC chemokine receptor (CCR) 4 and the CCR10 ligand cutaneous T cell-attracting chemokine (CTACK) in lymphocyte trafficking to inflamed skin. J Exp Med 2001, 194:1541-1547.

12. Fitzhugh DJ, Naik S, Caughman SW, Hwang ST: Cutting edge: C-C chemokine receptor 6 is essential for arrest of a subset of memory $T$ cells on activated dermal microvascular endothelial cells under physiologic flow conditions in vitro. J Immunol 2000, 165:6677-6681. 
13. Singh SP, Zhang HH, Foley JF, Hedrick MN, Farber JM: Human T cells that are able to produce IL-17 express the chemokine receptor CCR6. J Immunol 2008, 180:214-221.

14. Annunziato F, Romagnani S: Heterogeneity of human effector CD4+ T cells. Arthritis Res Ther 2009, 11:257.

15. Zhu J, Paul WE: Heterogeneity and plasticity of T helper cells. Cell Res 2010, 20:4-12

16. Kim CH, Rott L, Kunkel EJ, Genovese MC, Andrew DP, Wu L, Butcher EC: Rules of chemokine receptor association with $\mathrm{T}$ cell polarization in vivo. J Clin Invest 2001, 108:1331-1339.

17. Duhen T, Geiger R, Jarrossay D, Lanzavecchia A, Sallusto F: Production of interleukin 22 but not interleukin 17 by a subset of human skin-homing memory T cells. Nat Immunol 2009, 10:857-863.

18. Trifari S, Kaplan CD, Tran EH, Crellin NK, Spits H: Identification of a human helper $\mathrm{T}$ cell population that has abundant production of interleukin 22 and is distinct from $\mathrm{T}(\mathrm{H})-17, \mathrm{~T}(\mathrm{H}) 1$ and $\mathrm{T}(\mathrm{H}) 2$ cells. Nat Immunol 2009, 10:864-871.

19. Cosmi L, Annunziato F, Maggi E, Romagnani S, Manetti R: Chemoattractant receptors expressed on type $2 \mathrm{~T}$ cells and their role in disease. Int Arch Allergy Immunol 2001, 125:273-279.

20. Cosmi L, De Palma R, Santarlasci V, Maggi L, Capone M, Frosali F, Rodolico G, Querci V, Abbate G, Angeli R, Berrino L, Fambrini M, Caproni M, Tonelli F, Lazzeri E, Parronchi P, Liotta F, Maggi E, Romagnani S, Annunziato $F$ : Human interleukin 17-producing cells originate from a CD161+CD4+ T cell precursor. J Exp Med 2008, 205:1903-1916.

21. Kleinschek MA, Boniface K, Sadekova S, Grein J, Murphy EE, Turner SP, Raskin L, Desai B, Faubion WA, de Waal Malefyt R, Pierce RH, McClanahan T, Kastelein RA: Circulating and gut-resident human Th17 cells express CD161 and promote intestinal inflammation. J Exp Med 2009, 206:525-534.

22. Postlethwaite $A E$, Holness MA, Katai $H$, Raghow R: Human fibroblasts synthesize elevated levels of extracellular matrix proteins in response to interleukin 4. J Clin Invest 1992, 90:1479-1485.

23. Scaletti C, Vultaggio A, Bonifacio S, Emmi L, Torricelli F, Maggi E, Romagnani S, Piccinni MP: Th2-oriented profile of male offspring T cells present in women with systemic sclerosis and reactive with maternal major histocompatibility complex antigens. Arthritis Rheum 2002, 46:445-450

24. Parel Y, Aurrand-Lions M, Scheja A, Dayer JM, Roosnek E, Chizzolini C: Presence of CD4+CD8+ double-positive T cells with very high interleukin-4 production potential in lesional skin of patients with systemic sclerosis. Arthritis Rheum 2007, 56:3459-3467.

25. Atamas SP, Yurovsky W, Wise R, Wigley FM, Goter Robinson CJ, Henry P, Alms WJ, White B: Production of type 2 cytokines by CD8+ lung cells is associated with greater decline in pulmonary function in patients with systemic sclerosis. Arthritis Rheum 1999, 42:1168-1178.

26. Pernis AB: Th17 cells in rheumatoid arthritis and systemic lupus erythematosus. J Intern Med 2009, 265:644-652.

27. Kurasawa K, Hirose K, Sano H, Endo H, Shinkai H, Nawata Y, Takabayashi K, Iwamoto I: Increased interleukin-17 production in patients with systemic sclerosis. Arthritis Rheum 2000, 43:2455-2463.

28. Murata M, Fujimoto M, Matsushita T, Hamaguchi Y, Hasegawa M, Takehara K, Komura K, Sato S: Clinical association of serum interleukin-17 levels in systemic sclerosis: is systemic sclerosis a Th17 disease? J Dermatol Sci 2008, 50:240-242.

29. Radstake TR, van Bon L, Broen J, Hussiani A, Hesselstrand R, Wuttge DM, Deng Y, Simms R, Lubberts E, Lafyatis R: The pronounced Th17 profile in systemic sclerosis (SSc) together with intracellular expression of TGFbeta and IFNgamma distinguishes SSc phenotypes. PLoS One 2009, 4:e5903.

30. LeRoy EC, Black C, Fleischmajer R, Jablonska S, Krieg T, Medsger TA Jr, Rowell N, Wollheim F: Scleroderma (systemic sclerosis): classification, subsets and pathogenesis. J Rheumatol 1988, 15:202-205.

31. Scharffetter K, Kulozik M, Stolz W, Lankat-Buttgereit B, Hatamochi A, Sohnchen R, Krieg T: Localization of collagen alpha 1(I) gene expression during wound healing by in situ hybridization. J Invest Dermatol 1989, 93:405-412.

32. Hussein MR, Hassan HI, Hofny ER, Elkholy M, Fatehy NA, Abd Elmoniem AE, Ezz El-Din AM, Afifi OA, Rashed HG: Alterations of mononuclear inflammatory cells, CD4/CD8+ T cells, interleukin 1beta, and tumour necrosis factor alpha in the bronchoalveolar lavage fluid, peripheral blood, and skin of patients with systemic sclerosis. J Clin Pathol 2005, 58:178-184.

33. Giovannetti A, Rosato E, Renzi C, Maselli A, Gambardella L, Giammarioli AM, Palange P, Paoletti P, Pisarri S, Salsano F, Malorni W, Pierdominici M: Analyses of $\mathrm{T}$ cell phenotype and function reveal an altered $\mathrm{T}$ cell homeostasis in systemic sclerosis. Correlations with disease severity and phenotypes. Clin Immunol 2010, 137:122-133.

34. Chizzolini C: T cells, B cells, and polarized immune response in the pathogenesis of fibrosis and systemic sclerosis. Curr Opin Rheumatol 2008, 20:707-712.

35. Ouyang W, Rutz S, Crellin NK, Valdez PA, Hymowitz SG: Regulation and functions of IL-10 family cytokines in inflammation and diseases. Annu Rev Immunol 2011, 29:71-109.

36. Starner TD, Barker CK, Jia HP, Kang Y, MCCray PB Jr: CCL20 is an inducible product of human airway epithelia with innate immune properties. Am J Respir Cell Mol Biol 2003, 29:627-633.

37. Eyerich S, Eyerich K, Pennino D, Carbone T, Nasorri F, Pallotta S, Cianfarani F, Odorisio T, Traidl-Hoffmann C, Behrendt H, Durham SR, Schmidt-Weber CB, Cavani A: Th22 cells represent a distinct human T cell subset involved in epidermal immunity and remodeling. J Clin Invest 2009, 119:3573-3585.

38. Kagami S, Rizzo HL, Lee JJ, Koguchi Y, Blauvelt A: Circulating Th17, Th22, and Th1 cells are increased in psoriasis. J Invest Dermatol 2010, 130:1373-1383.

39. Nograles KE, Zaba LC, Shemer A, Fuentes-Duculan J, Cardinale I, Kikuchi T, Ramon M, Bergman R, Krueger JG, Guttman-Yassky E: IL-22-producing "T22" T cells account for upregulated IL-22 in atopic dermatitis despite reduced IL-17-producing TH17 T cells. J Allergy Clin Immunol 2009, 123:1244-1252.

40. Sonnenberg GF, Nair MG, Kirn TJ, Zaph C, Fouser LA, Artis D: Pathological versus protective functions of IL-22 in airway inflammation are regulated by IL-17A. J Exp Med 2010, 207:1293-1305.

41. Simonian PL, Wehrmann F, Roark CL, Born WK, O'Brien RL, Fontenot AP: $\gamma \delta$ T cells protect against lung fibrosis via IL-22. J Exp Med 2010, 207:2239-2253.

42. Fossiez F, Djossou O, Chomarat P, Flores-Romo L, Ait-Yahia S, Maat C, Pin JJ, Garrone P, Garcia E, Saeland S, Blanchard D, Gaillard C, Das Mahapatra B, Rouvier E, Golstein P, Banchereau J, Lebecque S: T cell interleukin-17 induces stromal cells to produce proinflammatory and hematopoietic cytokines. J Exp Med 1996, 183:2593-2603.

43. Wilson MS, Madala SK, Ramalingam TR, Gochuico BR, Rosas IO, Cheever AW, Wynn TA: Bleomycin and IL-1 beta-mediated pulmonary fibrosis is IL-17A dependent. J Exp Med 2010, 207:535-552.

44. Venkatachalam K, Mummidi S, Cortez DM, Prabhu SD, Valente AJ, Chandrasekar B: Resveratrol inhibits high glucose-induced PI3K/Akt/ERKdependent interleukin-17 expression in primary mouse cardiac fibroblasts. Am J Physiol Heart Circ Physiol 2008, 294:H2078-2087.

45. Yoshizaki A, Yanaba K, Iwata Y, Komura K, Ogawa A, Akiyama Y, Muroi E, Hara T, Ogawa F, Takenaka M, Shimizu K, Hasegawa M, Fujimoto M, Tedder TF, Sato S: Cell adhesion molecules regulate fibrotic process via Th1/Th2/Th17 cell balance in a bleomycin-induced scleroderma model. J Immunol 2010, 185:2502-2515.

46. Doreau A, Belot A, Bastid J, Riche B, Trescol-Biemont MC, Ranchin B, Fabien N, Cochat P, Pouteil-Noble C, Trolliet P, Durieu I, Tebib J, Kassai B, Ansieau S, Puisieux A, Eliaou JF, Bonnefoy-Bérard N: Interleukin 17 acts in synergy with B cell-activating factor to influence B cell biology and the pathophysiology of systemic lupus erythematosus. Nat Immunol 2009, 10:778-785.

47. Shen H, Goodall JC, Hill Gaston JS: Frequency and phenotype of peripheral blood Th17 cells in ankylosing spondylitis and rheumatoid arthritis. Arthritis Rheum 2009, 60:1647-1656.

48. Yang J, Chu Y, Yang X, Gao D, Zhu L, Wan L, Li M: Th17 and natural Treg cell population dynamics in systemic lupus erythematosus. Arthritis Rheum 2009, 60:1472-1483.

\section{doi:10.1186/ar3486}

Cite this article as: Truchetet et al: Increased frequency of circulating Th22 in addition to Th17 and Th2 lymphocytes in systemic sclerosis: association with interstitial lung disease. Arthritis Research \& Therapy 2011 13:R166. 